\title{
PERANAN AUTOMATIC VOLTAGE REGULATOR SEBAGAI PENGENDALI TEGANGAN GENERATOR SINKRON
}

\author{
Alimin Nurdin ${ }^{1)}$, Abdul Azis ${ }^{2)}$ Reri Aresta Rozal ${ }^{3)}$ \\ Prodi Teknik Elektro Fakultas Teknik Universitas PGRi Palembang \\ Email :aliminnurdin@univpgri-Palembang.@ac.id
}

\begin{abstract}
ABSTRAKGenerator sinkron merupakan mesin-mesin listrik yang berfungsi untuk mengkonversi energi mekanik menjadi energi listrik. Generator sinkron mempunyai permasalahan yaitu ketidakstabilan tegangan pada saat perubahan beban, sehingga dibuthkan peralatan yang dapat mengendalikan kestabilan tegangan generator sinkron yaitu Automatic Voltage Regulator(AVR).Automatic Voltage Regulator (AVR) merupakan sebuah divais pengatur tegangan yang digunakan pada generator sinkron untuk menyetabilkan tegangan keluaran yang dihasilkan dari generator sinkron. Automatic Voltage Regulator (AVR) bekerja dengan mengatur arus penguatan (excitacy) pada eksiter, apabila beban bertambah maka Automatic Voltage Regulator (AVR) akan memerintahkan eksiter untuk berkerja dengan menambah arus eksitasi sebaliknya apabila beban berkurang maka Automatic Voltage Regulator (AVR) akan memerintahkan eksiter untuk mengurangi arus eksitasi.
\end{abstract}

Kata kunci: Generator sinkron, AVR, Eksiter, Eksitasi

\begin{abstract}
Synchronous generators are electrical machines that function to convert mechanical energy into electrical energy. Synchronous generators have problems that are voltage instability when the load changes, so it requires equipment that can control the stability of the synchronous generator voltage, namely Automatic Voltage Regulator (AVR). Automatic Voltage Regulator $(A V R)$ is a voltage regulating device used in synchronous generators to stabilize the output voltage generated from a synchronous generator. Automatic Voltage Regulator (AVR) works by regulating the excitacy of the exciter, if the load increases then the Automatic Voltage Regulator $(A V R)$ will command the exciter to work by increasing the reverse excitation current if the load decreases then the Automatic Voltage Regulator (AVR) will command the exciter to reduce excitation flow.
\end{abstract}

Keywords: Synchronous generator, AVR, Exciter

\section{PENDAHULUAN}

\section{Latar Belakang}

Pembangkit tenaga listrik terdiri dari peralatan utama salah satunya adalah generator sinkron [6]. Generator sinkron memegang peranan penting dalam pembangkitan energi listrik ukuran besar. Sebagian besar energi listrik yang dipergunakan oleh konsumen untuk kebutuhan sehari-hari dihasilkan oleh generator phasa banyak (polyphase) yang ada di pusat pembangkit. Secara umum prinsip kerja generator sinkron adalah apabila berputarnya rotor yang diputar oleh penggerak mula (prime mover) dan stator yang dieksitasi pada kecepatan sama [8].

Generator sinkron mempunyaipermasalahan yaitu ketidakstabilan tegangan. Ketidakstabilan tegangan pada generator sinkron akanmenyebabkan ketidakstabilan sistem secara keseluruhan terutama kualitas sistem, kualitas dan kemampuan transfer daya dari pembangkit ke konsumen, kondisi terparah terjadinya mekanisme pelepasan bebandengan demikian maka diperlukan peralatan yang dapat mengendalikan kestabilan tegangan generator sinkron yaitu Automatic Voltage Regulator(AVR) [1]. 
Automatic Voltage Regulator (AVR) adalah sebuah divais pengatur tegangan yang digunakan pada generator sinkron untuk menyetabilkan tegangan keluaran yang dihasilkan dari generator sinkron. AVR memegang peranan penting dalam pembentukan tegangan terminal generotor sinkron dalam suatu pembangkit.

Adanya perubahan-perubahan beban akan menyebabkan tegangan output terminal generator berubah-ubah sehingga dibutuhkan alat penyetabil tegangan (AVR) dengan melihat nilai arus eksitasi pada penguat tegangan (eksiter). Persentase tegangan jatuh (drop tegangan) yang terjadi antara tegangan yang dibangkitkan generator terhadap tegangan ouput generator dapat dilihat dari nilai regulasi tegangan. peran dan penggunaan AVR sebagai pengendali tegangan generator sinkron Unit II Meidensha,

\section{TINJAUAN PUSTAKA}

\section{Generator sinkron}

\section{Definisi Generator Sinkron}

Generator Sinkron atau disebut juga alternator merupakan mesin listrik yang digunakan untuk mengkonversi energi mekanis(energi gerak) menjadi energi listrik(electric) melalui prosesinduksi elektomagnetik [2].Dikatakangeneratorsinkronkarena jumlah putaran rotornya sama dengan jumlah putaran medan magnet pada stator.

Kecepatan sinkron ini dihasilkan dari kecepatan putar rotor dengan kutub-kutub magnet yang berputar dengan kecepatan yangsamadengan medan putar pada stator. Kumparan medanpada generator sinkron terletak pada rotornya sedangkan kumparan jangkarnya terletak pada stator [10].

\section{Konstruksi Generator Sinkron}

Generator sinkronmengkonversienergi mekanik menjadi energi listrikbolak-baliksecara elektromagnetik. Energi mekanik berasal dari penggerak mula yang memutar rotor, sedangkan energi listrik dihasilkan dari proses induksi elektromagnetik yang terjadi pada kumparankumparan stator. Padagambar 1 dapat dilihatbentuk sederhana dari sebuah generator sinkron.

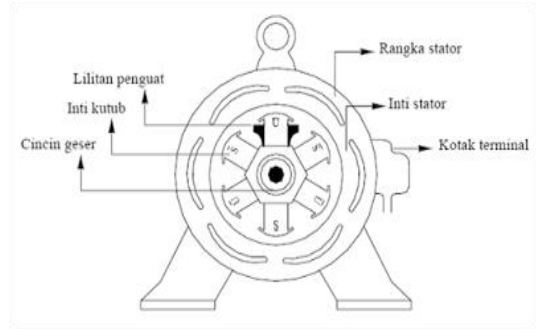

Gambar 1. Bentuk generator sinkron

Secara umum generator sinkron terdiri atas stator, rotor, dan celah udara bagian yang berputar. Celah udara adalah ruang antara stator dan rotor Pada bagian ini akan dibahas mengenai konstruksi generator sinkron secara garis besar. Bagian-bagian generator yang dibahas pada bagian ini antara lain Stator dan Rotor [4].

a. Stator

Stator (armature) adalah bagian yang berfungsi sebagai tempat untuk menerima induksi magnet dari rotor.Arus AC yang menuju ke beban disalurkan melalui stator.Komponen ini 
berbentuk sebuah rangka silinder denganlilitan kawat.Stator terdiri dari beberapa komponen utama, yaitu:

1) Rangka stator

Rangka stator merupakan rumah kerangka yang menyangga inti jangkar generator

2) Inti Stator

Inti stator terbuat dari laminasi-laminasibajacampuranatau besi magnetik khusus terpasang ke rangka stator

3) Alur (slot) dan Gigi

Alur dan gigi merupakantempat meletakkan kumparan stator.Ada 3(tiga) bentuk alur stator yaitu terbuka, setengah terbuka, dan tertutup.

4) Kumparan Stator (Kumparan Jangkar)

Kumparan jangkar biasanya terbuat dari tembaga kumparan ini merupakan tempat timbulnya ggl induksi.

b. Rotor

Pada rotor generator terdapat kumparan jangkar yang berfungsi membangkitkan gayagerak listrik yangdisearahkan melaluikomutator. Sumber listrik yang dihasilkan komutator dikeluarkan melalui sikat(brush). Rotor terdiri dari tiga komponen utama yaitu:

1) Slip Ring

Slip ring merupakan cincin logam yang melingkari porosrotor tetapi dipisahkan oleh isolasitertentu.Terminal kumparan rotor dipasang ke slip ringini kemudian dihubungkan ke sumber arus searah melalui sikat (brush)yang letaknya menempel pada slip ring.

2) Kumparan Rotor (Kumparan Medan)

Kumparan medan merupakan unsur yang memegang peranan utama dalam menghasilkan medan magnet. Kumparan ini mendapat arus searah dari sumber eksitasi tertentu

3) Poros Rotor

Poros rotor merupakan tempat meletakkan kumparan medan, dimana pada poros rotor tersebut telah dibentuk slot-slot secara paralel terhadap poros rotor.

\section{Prinsip Kerja Generator Sinkron}

Adapun prinsip kerja dari generator sinkron secara umum adalah [3]:

a. Kumparan medan yang terdapat pada rotor dihubungkan dengan sumber eksitasi tertentu yang akan mensuplai arus searah terhadap kumparan medan. Dengan adanya arus searah yang mengalir melalui kumparan medan maka akan menimbulkan fluks yang besarnya terhadap waktu adalah tetap.

b. Penggerak mula (Prime Mover) yang sudah terkopel dengan rotor segera dioperasikan sehingga rotor akan berputar pada kecepatan nominalnya.

c. Perputaran rotor tersebut sekaligus akan memutar medan magnet yang dihasilkan oleh kumparan medan. Medan putar yang dihasilkan pada rotor, akan diinduksikan pada kumparan jangkar sehingga pada kumparan jangkar yang terletak di stator akan dihasilkan fluks magnetik yang berubah-ubah besarnya terhadap waktu.

Adanya perubahan fluks magnetik yang melingkupi suatu kumparan akan menimbulkan ggl induksi pada ujung-ujung kumparan tersebut. 
Untuk generator sinkron tiga phasa, digunakan tiga kumparan jangkar yang ditempatkan di stator yang disusun dalam bentuk tertentu, sehingga susunan kumparan jangkar yang sedemikian akan membangkitkan tegangan induksi pada ketiga kumparan jangkar yang besarnya sama tapi berbeda fasa $120^{\circ}$ satu sama lain. Setelah itu ketiga terminal kumparan jangkar siap dioperasikan untuk menghasilkan energi listrik [4].

\section{Generator Sinkron Tanpa Beban}

Pada generator sinkron keadaaan beroperasi tanpa beban mengandung arti bahwa arus generator $I_{a}=0$. Dengan demikian besar tegangan terminal adalah [4]:

$$
E_{0}=N \frac{d \phi}{d t}
$$

\section{Generator Berbeban}

Dengan adanya beban yang terpasang pada outputgenerator sinkron, maka segera mengalir arus armatur $\mathrm{I}_{\mathrm{a}}$, dengan adanya arus armatur ini, pada kumparan armatur atau kumparan jangkar timbul flux putar jangkar. Flux putar jangkar ini bersifat mengurangi atau menambah flux putar yang dihasilkan oleh kumparan rotor. Hal ini tergantung pada faktor daya beban [4].

\section{Rangkaian Ekivalen Generator Sinkron}

Tegangan induksi $\mathrm{E}_{\mathrm{a}}$ dibangkitkan pada phasa generator sinkron. Tegangan ini biasanya tidak sama dengan tegangan yang muncul pada terminal generator. Tegangan induksi sama dengan tegangan output, hanya ketika tidak ada arus jangkar yang mengalir pada mesin. Beberapa faktor yang menyebabkan perbedaan antara tegangan induksi dengan tegangan terminal adalah [8]:

a. Distorsimedanmagnet pada cela udara oleh mengalirnya arus pada stator, disebut reaksi jangkar.

b. Induktansi sendiri kompuran jangkar.

c. Resistansi kumparan jangkar.

d. Efek permukaan rotor kutub sepatu.

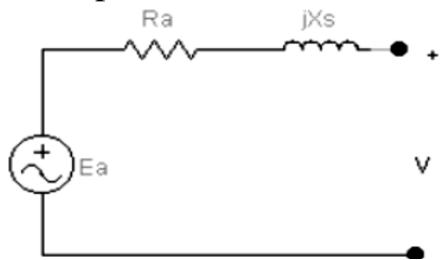

Gambar 2. Rangkaian ekuivalen generator sinkron perphasa

Hubungan yang terjadi antara tegangan terminal dengan tegangan $E_{a}$ adalah:

$$
E_{a}=V+I \cdot R_{a}+j I . X_{S}
$$

Sehingga saat tanpa beban, besarnya $I=0, \operatorname{dan} E_{a}=V$

\section{Automatic Voltage Regulator}

\section{Definisi Automatic Voltage Regulator (AVR)}

Automatic Voltage Regulator (AVR) adalah sebuah divais pengatur tegangan yang digunakan pada generator sinkron untuk menyetabilkan tegangan keluaran yang dihasilkan. 


\section{Konstruksi Automatic Voltage Regulator(AVR)}

Bagian AVR dibagi menjadi dua bagian utama yaitu [1]:

a. Bagian penyearah(rectifier) yang berfungsi mengubah energi AC menjadi DC yang dibutuhkan oleh generator sinkron dalam proses eksitasi. Pada bagian ini yang lebih diutamakan adalah kontrol sinyal yang untuk menyalakan transistor.

b. Bagian pengatur tegangan yang berfungsi sebagai pengontrol tegangan DC generator sinkron. Voltage regulator merupakan bagian terpenting dalam proses eksitasi pada generator sinkron. Pada bagian ini terdapat kontrol PI yang berfungsi untuk mengatur tegangan DC yangakandiinjeksikan pada medan generator sinkron. Masukan dari pengatur tegangan merupakan tegangan DC yang berasal dari penyearah serta tegangan refrensi yang diinginkan dengan kontrol PI yang digunakan maka didapat keluaran berupa tegangan eksitasi yang menjadi masukan generator sinkron.

\section{Fungsi Automatic Voltage Regulator (AVR)}

a. Menjaga kesetabilan tegangan output generator

b. Mengatur pembagian daya semu rektif saat kerja paralel

c. Memberikan pengaturan arus esitasi dalam kondisi gangguan supaya tidak keluar dari sinkronisasi

d. Menurunkan tegangan dengan cepat apabila generator terlepas dari beban yang akan mengakibatkan terjadinya over voltage [9].

\section{Prinsip kerja Automatic Voltage Regulator (AVR)}

Apabila tegangan output generator dibawah tegangan normal tegangan generator, maka AVRakan memperbesar arus pengutan (exitacy) pada exiter. Dengan demikian apabila terjadi perubahan tegangan output generator akan dapat distabilkan oleh AVR secara otomatis dikerenakan dilengkapi dengan peralataan seperti alat yang digunakan untuk pembatasan minimum ataupun maksimum yang bekerja secara otomati.Tiga keadaan AVR, yaitu [9]:

a. Jika tegangan output tinggi maka error signal(+) AVR akan memberian perintah untuk mengurangi arus eksitasi

b. Jika tegangan cocok dengan harga set point (0) maka AVR tidak akan memberikan perintah apapun

c. Jika tegangan output rendah maka error signalakan (-) maka AVR akan memberi perintah agar menambahkan arus eksitasi [9].

\section{Sistem eksitasi}

Sistem eksitasi adalah sistem mengalirnya pasokan listrik arus searah sebagai penguatan pada generator listrik,sehingga menghasilkan tenagalistrik dan besar tegangan keluaran bergantung pada besarnya arus eksitasi. Kontrolsystemeksitasimenghasilkantegangan emf generator. Oleh karena itu, kontrol tersebut tidak hanya untuk mengontrol power faktor, arus, dan perbaikan variabel lain. Sistem eksitasi pada generator listrik terdiri dari 2 macam, yaitu [9]:

1. Sistem eksitsi menggunakan sikat

Sistem eksitasi menggunakan sikat(brush excitation), sumber tenaga listrik berasal dari sumber listrik yang berasal dari generator arus searah (DC) atau generator arus bolakbalik(AC) yang disearahkan terlebih dahulu dengan menggunakan rectifier. Jika menggunakan sumber listrik yang berasal dari generator AC atau permanent Magnet 
Generator (PMG) medanmagnetnya adalah magnet permanent. Dalam lemari penyearah tegangan listrik arus bolakbalik diubah atau di searahkan menjadi tegangan arus searah untuk mengontrol kumparan medanexciter utama (main exciter). Untuk mengalirkan arus eksitasi dari main eksiter kerotor generator menggunakan slip ring dan sikat arang, demikian juga penyaluran arus yang berasal dari pilot exciter ke main exciter.

2. Sistem eksitasi tanpa menggunakan sikat

Penggunaan sikatatau slip ring untuk menyalurkan arus eksitasi kerotor generator eksitasi tanpa menggunakan sikat (brushless excitation).Keuntungan sistem eksitasi tanpa menggunakan sikat, antara lain adalah:

a. Energi yang diperlukan untuk eksitasi diperoleh dari poros utama (main shaft), sehingga keandalannya tinggi.

b. Biaya perawatan berkurang karena pada sistem eksitasi tanpa sikat (brushless excitation) tidak terdapat sikat, komutator dan slip ring.

Pada sistem eksitasi tanpa sikat (brushless excitation) tidak terjadi kerusakan isolasikarenamelekatnya debu karbon pada farnish akibat sikat arang.Mengurangi kerusakan (trouble)akibat udara buruk (bad atmosfere) sebab semua peralatan ditempatkan pada ruang tertutup.Selama operasi tidak diperlukan pengganti sikat, sehingga meningkatkan keandalan operasi dapat berlangsung kontinupada waktu yang lama. Pemutus medan generator (generator field breaker), field generator dan bus exciter atau kabel tidak diperlukan lagi.Biaya pondasi berkurang, sebab aluran udara dan bus exciter atau kabel tidak memerlukan pondasi.

\section{Pengatur Tegangan Generator}

Karena tegangan terminal generator AC banyak berubah dengan berubahnyabeban, maka untuk operasi hampersemua peralatan listrik diperlukan usaha untuk menjaga agar tegangannya konstan. Cara yang biasa dilakukan untuk ini adalah menggunakan alat pembantu yang disebut pengatur tegangan(voltageregulator) untuk mengendalikan besarnya eksitasi medanDC yang dicatukan pada generator. Bila tegangan terminal generator turunkarena perubahanbeban, pengatur tegangan secaraotomatis menaikkan pembangkitan medan sehinggategangan kembali normal. Sama halnyabilategangan terminal naikkarenaperubahan beban,pengatur mengembalikan nilai tegangannormalnya dengan mengurangi eksitasimedan.

Hampir semua pemgatur teganganmengendalikan eksitasi medangeneratorsecara tak langsung yaitu dengan mengoperasikan rangkaian pegeksitasi medan. Arus yang harus ditangani oleh pengatur jauh lebih kecil dalam rangkaianmedan pengeksitasi daripada dalam rangkaian medangenerator. Salah satu tipe pengatur tegangan generator adalah jenis tahanan geser kerja langsung. Pada dasarnya pengatur ini terdiri dari tahanan variabel yang dikendalikan secara otomatis dalam rangkaianmedan pengeksitasi. Elemen tahanangeser yang dihubungankan seri dengan pengeksitasi medan terdiri dari tumpukan blok tahanan atau wafer bukan logam, ditumpuk sehingga tahanan dari tumpukan dapat diubah jika dimiringkan kedepan atau kebelakang oleh elemen kopel. Prinsip kerja pengatur tegangan statik sama seperti jenis tahanan geser kerja langsung, yaitu tegangan generator ac diatur dengan megubah tahanan efektif dalam rangkaian medan pengeksitasi, yang selanjutnya megubah keluaran tegangan dari pengeksitasi tersebut. 


\section{METODE PENELITIAN}

\section{Menentukan Kecepatan Putaran Generator}

Nilaikecepatan putaran generator dapat ditentukan dengan menggunakan persamaan sebagai berikut[3]:

$$
n=\frac{120 \cdot f}{p}
$$

\section{Menentukan Tahanan Generator Eksiter}

Tahanan generator eksiter dapat ditentukan dengan menggunakan persamaan sebagai berikut [3]:

$$
R_{f}=\frac{V_{f}}{I_{f}}
$$

\section{Menentukan Tegangan Eksitasi Pada Eksiter Per Jam}

Teganganeksitasi pada eksiter per jam dapat ditentukan dengan menggunakan persamaan sebagai berikut [2]:

$$
E_{f}=n \cdot c \cdot \phi
$$

\section{Menentukan Arus Eksitasi Pada Eksiter Per Jam}

Aruseksitasi pada eksiter per jam dapat ditentukan dengan menggunakan persamaan sebagai berikut [2]:

$$
I_{f}=\frac{E_{f}}{R_{f}}
$$

\section{Menentukan Tegangan Generator Tanpa Beban}

Regulasi tegangan merupakan perubahan tegangan jepit atau tegangan terminal pada generator sinkron dalam keadaan tanpa beban dan beban penuh.Tegangan generator tanpa beban dapat ditentukan dengan menggunakan persamaan sebagai berikut [2]:

$$
E_{0}=n \cdot c \cdot \phi
$$

\section{Menentukan Persentase Regulasi Tegangan}

Persentaseregulasi tegangan dapat ditentukan dengan menggunakan persamaan sebagai berikut [3]:

$$
\Delta V(\%)=\left(\frac{E_{0}-V}{V}\right) \cdot 100 \%
$$

\section{HASIL DAN PEMBAHASAN}

PLTGU Gunung Megang adalah perusahan yang dimiliki oleh PT MEPPO-GEN dan di operasikan oleh PT Sumberdaya sewatama, yang beralamatkan di Jalan Lintas Palembang Muara Enim, Desa Panang Jaya, Kecamatan Gunung Megang, Kabupaten Muara Enim, Provinsi Sumatera Selatan.

PLTGU Gunung Megang yang dimiliki oleh PTMeppo-Gen dioperasikan pada tahun 2007. Pengoperasi PLTGU Gunung Megang dilakukan langsung oleh karyawan PTMeppo-Gen. PLTGU Gunung Megang yang berkafasitas 110 MW pada awal beroperasinya PLTGU Gunung Megang memiliki kapasitas 80 MW yang terdiri dari 2 GTG (gas turbin generator).

Dengan bertambahnya kebutuhan masyarakat dalam bidang ketenaga listrikan pada tahun 2014 PLTGU Gunung Megang menambah satu buah unit generator berdaya 30 MW (STG) dengan memanfaatkan gas buang dari dua Unit GTG dengan demikian maka bertambah juga kapasitas daya yang dihasilkan oleh PLTGU Gunung Megang menjadi 110 MW. 
Tabel 1.Data Generator Utama

\begin{tabular}{|l|l|}
\hline \multicolumn{1}{|c|}{ Merek } & \multicolumn{1}{c|}{ Meidensa Syncrhronous Generator } \\
\hline Output & $63.000 \mathrm{kVA}$ \\
\hline Putaran & $3.000 \mathrm{Rpm}$ \\
\hline Frekuensi & $50 \mathrm{~Hz}$ \\
\hline Tegangan 1 phasa & $11.500 \mathrm{~V}$ \\
\hline Tegangan 3 phasa & $34.500 \mathrm{~V}$ \\
\hline Tegangan eksitasi & $321 \mathrm{~V}$ \\
\hline Phasa & 3 \\
\hline Pule & 2 \\
\hline Power faktor & $80 \%$ \\
\hline Field ampere & $529 \mathrm{~A}$ \\
\hline Date & 2005 \\
\hline
\end{tabular}

Tabel 2. Data Beban Harian Generator Utama Dan Eksiter

\begin{tabular}{l|c|c|c|c|c|c}
\hline \multirow{2}{*}{ Jam } & \multicolumn{7}{|c}{ Generator Utama } \\
\cline { 2 - 7 } & $\boldsymbol{f}(\mathbf{H z})$ & $\boldsymbol{V}(\mathbf{k V})$ & $\boldsymbol{I}(\mathbf{k A})$ & $\boldsymbol{P}(\mathbf{M W})$ & $\boldsymbol{Q}(\mathbf{M V A R})$ & $\mathbf{C o s} \boldsymbol{\varphi}$ \\
\hline $01: 00$ & 50,26 & 34,34 & 5,353 & 35,09 & 4,54 & 0,99 \\
\hline $02: 00$ & 49,79 & 34,40 & 5,330 & 34,91 & 5,05 & 0,99 \\
\hline $03: 00$ & 50,24 & 34,40 & 5,334 & 35,05 & 4,49 & 0,99 \\
\hline $04: 00$ & 50,24 & 34,39 & 5,321 & 34,91 & 4,77 & 0,99 \\
\hline $05: 00$ & 50,04 & 34,24 & 5,350 & 34,91 & 4,77 & 0,99 \\
\hline $06: 00$ & 49,92 & 33,99 & 5,394 & 35,00 & 4,63 & 0,99 \\
\hline $07: 00$ & 50,18 & 33,98 & 5,425 & 35,09 & 5,23 & 0,99 \\
\hline $08: 00$ & 50,24 & 34,05 & 5,323 & 34,59 & 4,68 & 0,99 \\
\hline $09: 00$ & 50,26 & 33,90 & 5,187 & 33,53 & 4,72 & 0,99 \\
\hline $10: 00$ & 50,05 & 33,79 & 5,153 & 33,11 & 5,14 & 0,99 \\
\hline $11: 00$ & 50,46 & 33,66 & 5,097 & 32,65 & 4,86 & 0,99 \\
\hline $12: 00$ & 50,09 & 33,53 & 5,145 & 32,84 & 4,95 & 0,99 \\
\hline $13: 00$ & 50,12 & 33,53 & 5,036 & 32,01 & 5,55 & 0,99 \\
\hline $14: 00$ & 50,24 & 33,41 & 5,071 & 32,28 & 4,68 & 0,99 \\
\hline $15: 00$ & 50,07 & 33,44 & 5,039 & 32,14 & 4,12 & 0,99 \\
\hline $16: 00$ & 50,36 & 33,69 & 5,001 & 32,24 & 3,66 & 0,99 \\
\hline $17: 00$ & 50,25 & 33,73 & 5,083 & 32,74 & 3,71 & 0,99 \\
\hline $18: 00$ & 50,00 & 33,92 & 5,185 & 33,52 & 4,86 & 0,99 \\
\hline $19: 00$ & 49,81 & 33,77 & 5,209 & 33,90 & 3,76 & 0,99 \\
\hline $20: 00$ & 50,04 & 33,89 & 5,276 & 33,76 & 6,75 & 0,99 \\
\hline $21: 00$ & 50,02 & 33,86 & 5,309 & 34,08 & 6,01 & 0,99 \\
\hline $22: 00$ & 50,30 & 33,78 & 5,238 & 33,71 & 4,86 & 0,99 \\
\hline $23: 00$ & 50,24 & 33,92 & 5,211 & 33,71 & 4,63 & 0,99 \\
\hline $24: 00$ & 50,32 & 34,16 & 5,257 & 34,31 & 4,45 & 0,99 \\
\hline
\end{tabular}

Tabel 3.Hasil PerhitunganKecepatanGenerator

\begin{tabular}{|l|l|l|l|}
\hline Jam & $\boldsymbol{n}$ & Jam & $\boldsymbol{n}$ \\
\hline $01: 00$ & 3.016 & $13: 00$ & 3.007 \\
\hline $02: 00$ & 2.987 & $14: 00$ & 3.014 \\
\hline $03: 00$ & 3.014 & $15: 00$ & 3.004 \\
\hline
\end{tabular}




\begin{tabular}{|l|l|l|l|}
\hline $04: 00$ & 3.014 & $16: 00$ & 3.022 \\
\hline $05: 00$ & 3.002 & $17: 00$ & 3.015 \\
\hline $06: 00$ & 2.995 & $18: 00$ & 3.000 \\
\hline $07: 00$ & 3.011 & $19: 00$ & 2.989 \\
\hline $08: 00$ & 3.014 & $20: 00$ & 3.002 \\
\hline $09: 00$ & 3.016 & $21: 00$ & 3.001 \\
\hline $10: 00$ & 3.003 & $22: 00$ & 3.018 \\
\hline $11: 00$ & 3.028 & $23: 00$ & 3.014 \\
\hline $12: 00$ & 3.005 & $24: 00$ & 3.019 \\
\hline
\end{tabular}

nilai tahanan pada generator eksiter $R_{f} 0,6068 \Omega, c \phi 0,107$

Tabel 4.Hasil Perhitungan TeganganEksitasi DanArus Eksitasi Pada Eksiter

\begin{tabular}{|c|c|c|c|c|c|}
\hline \multirow{2}{*}{ Jam } & \multicolumn{2}{|c|}{ Generator eksiter } & \multirow{2}{*}{ Jam } & \multicolumn{2}{c|}{ Generator eksiter } \\
& $\mathbf{V}(\mathbf{V})$ & $\mathbf{I}(\mathbf{A})$ & & $\mathbf{V}(\mathbf{V})$ & $\mathbf{I}(\mathbf{A})$ \\
\hline $01: 00$ & 322,712 & 531,8216 & $13: 00$ & 321,749 & 530,2346 \\
\hline $02: 00$ & 319,609 & 526,7079 & $14: 00$ & 322,498 & 531,4689 \\
\hline $03: 00$ & 322,498 & 531,4689 & $15: 00$ & 321,428 & 529,7056 \\
\hline $04: 00$ & 322,498 & 531,4689 & $16: 00$ & 323,354 & 532,8796 \\
\hline $05: 00$ & 321,214 & 529,3529 & $17: 00$ & 322,605 & 531,6453 \\
\hline $06: 00$ & 320,465 & 528,1186 & $18: 00$ & 321,000 & 529,0003 \\
\hline $07: 00$ & 322,177 & 530,9399 & $19: 00$ & 319,823 & 527,0606 \\
\hline $08: 00$ & 322,498 & 531,4689 & $20: 00$ & 321,214 & 529,3529 \\
\hline $09: 00$ & 322,712 & 531,8216 & $21: 00$ & 321,107 & 529,1766 \\
\hline $10: 00$ & 321,321 & 529,5293 & $22: 00$ & 322,926 & 532,1743 \\
\hline $11: 00$ & 323,996 & 533,9376 & $23: 00$ & 322,498 & 531,4689 \\
\hline $12: 00$ & 321,535 & 529,8819 & $24: 00$ & 323,033 & 532,3506 \\
\hline
\end{tabular}

\section{Perhitungan Persentase Regulasi Tegangan}

Untuk mengetahui regulasi tegangan output generator selama 24 jam, nilai konstanta generator utama

$$
K=\frac{E_{0}}{n \cdot I_{f}}=\frac{34.500}{(3.000) \cdot(529)}=0,0217
$$

Tabel 5.Hasil Perhitungan Tegangan Generator Tanpa Beban Dan Persentase Regulasi Tegangan

\begin{tabular}{|c|c|c|c|c|c|}
\hline Jam & $\mathbf{E}_{\boldsymbol{0}}(\mathbf{V})$ & $\Delta \mathbf{V}(\boldsymbol{\%})$ & $\mathbf{J a m}$ & $\mathbf{E}_{\boldsymbol{0}}(\mathbf{V})$ & $\Delta \mathbf{V}(\boldsymbol{\%})$ \\
\hline $01: 00$ & $34.806,2346$ & 1,36 & $13: 00$ & $34.598,8151$ & 3,18 \\
\hline $02: 00$ & 34.140 .0910 & $-0,76$ & $14: 00$ & $34.760,0856$ & 4,04 \\
\hline $03: 00$ & $34.760,0856$ & 1,05 & $15: 00$ & $34.529,8130$ & 3,26 \\
\hline $04: 00$ & $34.760,0856$ & 1,08 & $16: 00$ & $34.944,8587$ & 3,73 \\
\hline $05: 00$ & $34.483,8477$ & 0,71 & $17: 00$ & $34.783,1510$ & 3,12 \\
\hline $06: 00$ & $34.323,2110$ & 0,98 & $18: 00$ & $34.437,9110$ & 1,53 \\
\hline $07: 00$ & $34.690,9228$ & 2,09 & $19: 00$ & $34.185,8357$ & 1,23 \\
\hline $08: 00$ & $34.760,0856$ & 2,09 & $20: 00$ & $34.483,8477$ & 1,75 \\
\hline $09: 00$ & $34.806,2346$ & 2,67 & $21: 00$ & $34.460,8798$ & 1,78 \\
\hline $10: 00$ & $34.506,8297$ & 2,12 & $22: 00$ & $34.852,4142$ & 3,18 \\
\hline $11: 00$ & $35.083,7583$ & 4,23 & $23: 00$ & $34.760,0856$ & 2,48 \\
\hline $12: 00$ & $34.552,8039$ & 3,05 & $24: 00$ & $34.875,5122$ & 2,10 \\
\hline
\end{tabular}


Dari data perhitungan nilai arus eksitasi diatas dapat diketahui bahwa besarnya nilai arus eksitasi dipengaruhi oleh besarnya tegangan keluar generator, jumlah putaran generator dan beban generator. Semakin besar putaran generator semakin besar nilai tegangan dan arus eksitasi pada generator eksiter, seperti pada jam 02:00dengan kecepatan putaran $2.987 \mathrm{Rpm}$, tegangan keluar 34,40 kV dan beban 34,91 MW dengan nilai arus eksitasi sebesar 526,7079 A sedangkan pada jam 11:00dengan kecepatan putaran $3028 \mathrm{Rpm}$, tegangan keluar 33,66 kV dan beban 32.65 MW dengan nilai arus eksitasi 533,9376 A

Dari data perhitungan nilai persentase regulasi tegangan diatas dapat diketahui bahwa besarnya persentase regulasi tegangan dipengaruhi oleh beberapa hal diantaranya yaitu besarnya nilai arus eksitasi dan frekuensi generator. Semakin besar frekuensi generator maka semakin besar kecepatan generator. Semakin besar nilai kecepatan generator dan nilai arus eksitasi maka semakin besar tegangan generator tanpa beban selain itu persentase regulasi tegangan juga dipengaruhi oleh tegangan terminal. Apabila tegangan generator tanpa beban tinggi dan tegangan terminal kecil maka semakin besar nilai pesentase regulasi tegangan sebaliknya apabila tegangan generator tanpa beban kecil dan tegangan terminal makin besar maka nilai persentasenya semakin kecil, seperti pada jam 02:00 dengan frekuensi 49,79 Hz, nilai arus eksitasi 526,7079, kecepatan putaran generator 2.987,tegangan generator tanpa beban $34.140,0910 \mathrm{~V}$ dan tegangan terminal generator $34.400 \mathrm{~V}$ dengan nilai persentase regulasi tegangan -0,76\% sedangkan pada jam 11:00 dengan frekuensi 50,46 Hz, arus eksitasi 533,9376, kecepatan putaran generator $3.028 \mathrm{Rpm}$, tegangan generator tanpa beban $35.083,7583 \mathrm{~V}$ dan tegangan terminal generator $33.660 \mathrm{~V}$ dengan nilai persentase regulasi $4,23 \%$

Nilai persentase regulasi tegangan tidak boleh melebihi batas nilai persentase regulasi tegangan $\pm 20 \%$.Dengan melihat nilai terendah dan nilai tertinggi dari persentase regulasi tegangan generator Unit II Meidensha tersebut maka nilai regulasi tidak melebihi batas persentase regulasi tegangan generator yang di izinkan perusahaan.Dari nilai persentase regulasi tegangan tersebut maka berarti autometic voltage regulator (AVR) bekerja dengan baik dan automatic voltage regulator (AVR) berperan dalam pengendalian tegangan generator Unit II Meidensha.

Nilai arus eksitasi tertinggi terjadi pada jam 11:00dengan kecepatan putaran $3.028 \mathrm{Rpm}$, tegangan keluar 33,66 $\mathrm{kV}$ dan beban 32,65 MW dengan nilai arus eksitasi 533,9376 A.Nilai arus eksitasi terendah 02:00 dengan kecepatan putaran 2.987 Rpm, tegangan keluar 34,40 kV dan beban 34,91 MW dengan nilai arus eksitasi sebesar 526,7079 A.

\section{KESIMPULAN}

1. Besarnya nilai arus eksitasidipengaruhi oleh kecepatan putaran dan beban generator Unit II Meidensha.

2. Nilai toleransi persentase regulasi tegangan yang ditetapkan perusahaan adalah $\pm 20 \%$, dengan melihat nilai persentasi regulasi tegangan terendah dan tertinggi disimpulkan bahwa nilai persentase regulasi tegangan masih dalam keadaan normal dan tidak melebihi nilai toleransi yang ditetapkan perusahaan sehingga AutomaticVoltage Regulator(AVR) bekerja dengan baik sebagai pengendalian tegangan generator Unit II Meidensha. 


\section{DAFTAR PUSTAKA}

[1] Alam, Abd. Ashal., Syahrial, Nandang Taryana. 2015. Pemodelan dan Simulasi Automatic Voltage Regulator untuk Generator Sinkron 3 kVA Berbasis Proportional Integral. Jurnal Reka Elkomika, Vol.3, No.2,Juli 2015, hlm. 97-110, ISSN: 2337-439X.

[2] Chapman, S.J. 1985. Electric Machinery Fundamentals. Singapore: McGraw-Hill, Inc.

[3] Fitzgerald, A.E. et al. 1997.Mesin-Mesin Listrik. Jakarta:Erlangga.

[4] Lister, Eugene C. 1998. Mesin dan Rangkaian Listrik, Edisi Keenam. Jakarta: Erlangga.

[5] Marsudi, Djiteng.2005.Pembangkitan Energi Listrik. Jakarta:Erlangga.

[6] Meppo-gen.2012.Buku Paduan Operasi dan Pemeliharaan.PTMeppo-Gen.

[7] Meidensha Corporation.2004.Manual Book. Tokyo:Meidensha Coorporation.

[8] Priyadi, Irnanda. 2012.Analisis Pengaruh Eksitasi Terhadap Efek Harmonisa Pada Hubungan Belitan Generator Sinkron Dengan Behan LHE. Jurnal Ilmiah Bidang Teknik Elektro dan Komputer AMPLIFIER, Volume 2 Nomor 1, Mei 2012, hlm. 40-44, ISSN: 2089-2020.

[9] Robandi,Imam.2009. Modern Power System Control. Yogyakarta: Andi Offset.

[10] Simanjuntak, Basofi.,Syamsul Amien. 2014. Studi Pengaruh Arus Eksitasi Pada Generator Sinkron Yang Bekerja Paralel Terhadap Perubahan Faktor Daya. Jurnal Singuda Ensikom Vol. 7, No. 1, April 2014, hlm. 8-15, ISSN: 2337-3237. 